\title{
Study of the tsunami wave run-up using dimensional analysis
}

\author{
Hiba A. Bachay ${ }^{1, *} \mid$ Asad H. Aldefae ${ }^{1} \mid$ Salah L. Zubaidi ${ }^{1}$
}

\section{Affiliations}

Department of Civil Engineering, University of Wasit, Wasit, Iraq

Correspondence Hiba Ali Bachay, Department of Civil Engineering, University of Wasit, Wasit, Iraq Email: hibab301@uowasit.edu.iq

\section{Received}

20-August-2021

Revised

14-October-2021

Accepted

16-October-2020

\begin{abstract}
Tsunamis are among the most severe natural hazards known to man, and they have claimed thousands of lives and destroyed vast amounts of property throughout history. Several previous researches studied the tsunami wave runup and its inundation to the coasts and their effect on the coastal communities. In the current study, the Dimensional analysis (DA) method was used for formulating rational hypotheses for the complicated physical conditions connected to the wave run-up study. Pairs of empirical formulas were derived: the first one for the non-dimensional wave run-up over a sandy beach, and the other for the wave run-up over the armoured beach. Based on the obtained experimental results, which were adopted as an input data for the program of IBM SPSS Statistics, v26, both formulas showed a good agreement as the coefficients of correlation were 0.93 and 0.98 , respectively.
\end{abstract}

\section{Doi: $10.31185 /$ ejuow.Vol9.Iss2.270}

Kevwords: Run-up. sandv beach. armoured beach. dimensional analvsis.

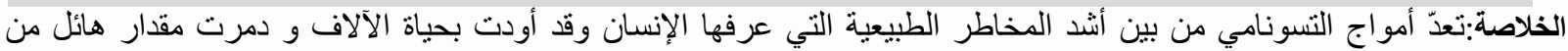

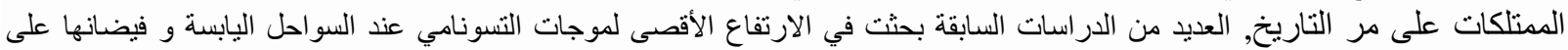

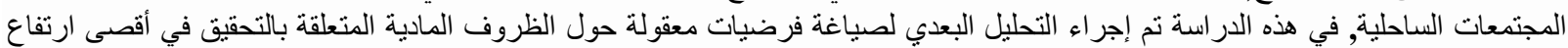

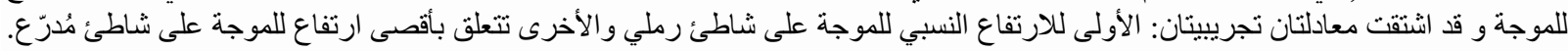

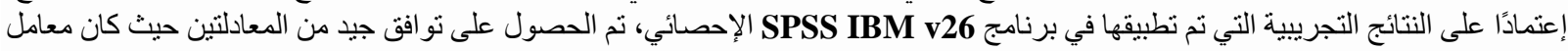
الارتباط 0.93 و 0.98 على التو التي.

\section{INTRODUCTION}

The Andaman tsunami on 26 December 2004 was considered to be one of the most devastating natural disasters in the Asian region. This has contributed to the deaths of around a quarter of a million people around the world. The tsunami claimed more than 220,000 lives and destroyed the homes of a total of 800,000 people. In recent years, engineers and scientists have established and shown greater interest in researching potential tsunami events that may affect the coastal regions of their respective countries [1]. As a result of recent events in the Indian Ocean and the Japan tragedy, humanity is concerned about the threat presented by tsunamis after earthquakes. A team of scientists is investigating a unique form of the tsunami caused by huge undersea landslides to see if its incidence is influenced by climate change. [2]. Climate change has been hypothesized to increase the incidence of slides in two ways. The first is methane hydrate dissociation (the release of methane gas from a previously stable state in the sediment), which can result in structural damage and a slide [3]. The alternative way is a crustal rebound, in which the loss of the ice sheet allows pressure in the Earth's crust to release, allowing it to return to a new equilibrium [4]. Independent of ETTs (earthquake-triggered tsunamis), global warming, which is a long-term phenomenon, is predicted to result in an accelerated increase in SLR (sea level rise) [5]. Thus, NASA's research of the 15 hottest years since 2001 may be connected to the huge increase in earthquake frequency from 2001 to 2016 , which has resulted in glaciers, sea ice melting, and sea level rising at an alarming rate of 85.5mm [4]. Landslides or earthquakes have generated the majority of tsunamis (about 88\%) in the Database of Global Historical Tsunami (since 1900 A.D.). A large earthquake under or above the ocean's surface is the primary cause of a tsunami [6]. 
In a laboratory channel, Gedik et al. [7] investigated the tsunami run-up on permeable slope beaches. A natural sandy beach with a diameter of $0.35 \mathrm{~mm}$ and a specific gravity of 2.63 was developed. On permeable slope beaches, various types of armour units with diameters and specific gravities ranging from 10-13.8 mm and 2.3182.289 , respectively, were mounted. The beach had a 1:5 incline. Tsunami run-up heights for permeable (armoured and non-armoured) beaches were investigated. Armour units trigger a 50\% reduction in run-up height, according to the findings of these tests. The dimensional analysis was also used to estimate the tsunami wave run-up on armoured and sandy beaches. Two empirical equations were estimated and gave very good agreement. Ghasemi [8] used dimensional analysis and obtained an equation to calculate tsunami wave energy and compared the results to the 26 December 2004 tsunami in Sumatra. He also calculates the wave height near the coastlines. The author found that the relations estimated the wave height with an acceptable error as such estimated for three tsunamis and compared with reported values. Charvet et al. [9] applied the dimensional analysis method (depending on experimentally measured potential energy, wave amplitudes, and wavelength) for identifying correlated measurements. The statistical analysis was adopted for calculating the power-law relation between the run-up and waveform measurements, and for testing the importance of the power-law hypothesis. The obtained results explained how both the wave shape and wavelength affect the distance of run-up. One can notice that the linear relationship for the predicted and determined values were strong enough with a coefficient of determination $\left(\mathrm{R}^{2}\right)$ of 0.94 . Synolakis [10] studied the solitary waves on plane beaches as they run-up. For non-breaking waves. An approximate hypothesis was presented and asymptotic results for the maximum runup of long waves were obtained. Breaking and non-breaking waves were found to have different runup regimes. A breaking criterion was developed for deciding whether a solitary wave will break as it climbs up a sloping beach, and a related criterion was introduced for determining whether the wave will break during rundown. These findings were used to justify some of the observational runup interactions that still exist.

Trying to cover some of the effective parameters that were not explored in the reviewed researche, the dimensional analysis was conducted in this study, where important dimensionless parameters for tsunamis wave run-up were obtained and studied. In addition, the obtained empirical equations were compared to the experimental measurements.

\section{EXPERIMENTAL WORK}

Many prior scholars have created channel models of various materials and dimensions for use in hydraulic investigations, and these models have been documented in detail [11,12].

The experiments were conducted out on a wave simulator that was built particularly for this purpose, with transparent sides and a length, width, and height of 6.0, 0.8, and 1.0 meter, respectively. All of the experiments were carried out at Wasit University's hydraulics laboratory, which is part of the engineering college. The shoreline understudy has a slope of $1 \mathrm{~V}: 10 \mathrm{H}$ and was built with natural sand. Figure 1 depicts the experimental setup. Tsunamis are caused by a rapid large-scale disruption of a large volume of ocean water, which displaces the ocean's surface and creates a sequence of waves that branch out from the disturbance [13]. The wave generator was used to replicate the sudden movement that occurs under the ocean's surface. A wave flume, sealed tank, pump, control valve, and Plexiglas make up the basic construction of the simulator system. The present wave simulator was inspired by a pneumatic wave generator capable of creating lengthy waves and pulling down waves. To do this, the tsunami simulator pulls a regulated volume of water from a wave basin into a container and releases it over time. An air pump linked to the tank provides continual suction, and the air pressure within the tank is controlled by a separate motor-operated valve. It also needs a new pump to produce waves, rather than a wave basin, in the channel. In addition to these changes, the concepts behind the new wave simulator are basically the same as those of Wilkie and Young [14]. The tsunami generator is controlled by a motorized valve that changes the tank's pressure. The air pump maintains constant suction. When the control valve (CV) is closed, water is pulled into the tank from the channel and released when the valve is opened. To avoid damage to the air pump, it must keep the water level from rising to the top of the tank and being sucked into it. The draw-up point creates the negative dip in the channel, while the water discharged produces the positive half of the wave. Runup may be measured using a special tape that is placed along the flume's wall and is graded in centimetres. The tape end marked (0) is affixed at the toe of the bathymetry, and the shore position for a constant level of water is computed for each experiment. The ultimate inundation point along the angle slope is provided for each stroke, and the runup $\mathrm{R}$ is computed as follows [9]:

$$
R=R_{l} \tan \beta
$$

Where $R_{l}$ is the inundation distance.

In the same way, tsunami wave height was measured by tap placed vertically at the sides of each flume window and, from the high-speed video camera, the wave height was determined. The sand raining technique (i.e., air 
pluviation) is used to prepare the bed soil of the model in the channel, in which sand particles fall down the model from an acceptable height and the ideal opening slot varies between $2 \mathrm{~mm}$ and $7 \mathrm{~mm}$. This approach is often utilized in the preparation of various models. $[15,16]$.

The mean particle size and specific gravity of a typical sandy coast model were $0.28 \mathrm{~mm}$ and 2.67 , respectively, in experiments. Armoured coastlines were created by placing $5 \mathrm{~cm}$ thick armour units (big gravel with a diameter of $14 \mathrm{~mm}$ ) along the full slope of the original sandy shoreline.

The tsunami waves classified as shallow water waves [13], so the water depth in the channel is subject to the limit that the generate waves in shallow water $(\mathrm{d} / \mathrm{L}<0.05)[13]$, where the water depth in the wave flume ranged between (0.2-0.25) $\mathrm{m}$, and the channel length was 6 meters, which can be considered as a wavelength (from its propagation until its collision with the model structure).

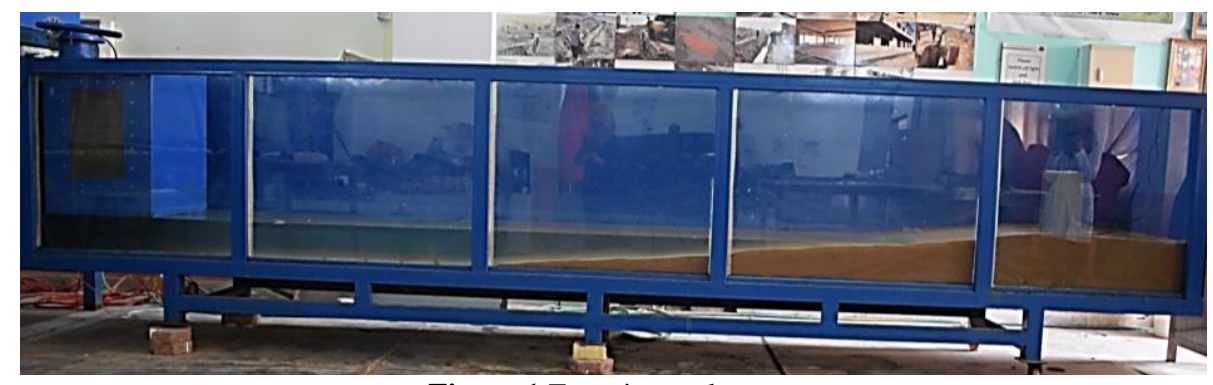

Figure 1 Experimental setup.

\section{DIMENSIONAL ANALYSIS}

Dimensional analysis is frequently utilized in virtually any engineering challenge to investigate the dimensions of various physical variables. This method is used to gather data on huge complex systems as well as to verify mathematical and physical calculations. Due to the difficulty of converting units from one-dimensional unit to another, dimensional analysis is used to create connections between distinct physical quantities by identifying their fundamental dimensions, such as mass, M, length, L, and time, T. Dimensional analysis is used to check if derivative equations are acceptable and to create plausible assumptions about complicated physical situations that may be validated by testing [17]. The dimensional analysis was done twice in this study, once for the wave run-up over the sandy beach and once for the run-up over the armoured beach.

\subsection{Buckingham's Pi theorem}

To describe the dimensionless groups of the chosen variables of the studied problem, Buckingham's theorem was used. The theorem asserts the solution of the equation is in the shape of $\mathrm{F}\left(\pi_{1}, \pi_{2}, \pi_{3}, \ldots \pi_{\mathrm{n}-\mathrm{k}}\right)=0$ when the equation $\mathrm{F}\left(\mathrm{q}_{1}, \mathrm{q}_{2}, \mathrm{q}_{3}, \ldots,\right)=$ zero is complete, and its terms are independent vectors of the variables $\mathrm{q}_{1}, \mathrm{q}_{2}$, $\mathrm{q}_{3}$, etc., and are dimensionless as a basic dimension. A full-dimensional homogeneous equation involving (n) physical quantities operating in terms of $(\mathrm{m})$ basic quantities is equivalent to a mathematical connection between (n-m) as dimensionless groups in mathematical terms. For example, if the link between the physical problem and three (3) fundamental physical quantities involves nine (9) physical quantities, six (6) sets of dimensionless groups are produced.

\subsection{Dimensional variables}

The primary stage in the method of dimensional analysis is determining the variables that influence the wave runup depending on the factors governing the height of wave run-up. These factors involve geometric, morphological, and hydraulic factors as well as the influence of the duration of flow. Hydraulic parameters involve variables connected to the characteristics of flo. They are the density of fluid $\left(\gamma_{w}\right)$, gravitational acceleration (g) and flow depth (D). The morphological parameters include variables related to soil properties; soil density $\left(\gamma_{s}\right)$ and sand particles diameter $\left(D_{s}\right)$. Geometric factors involve variables linked to the beach shape, represented by beach slope $(\beta)$. Finally, the wave characteristics will be considered as dependent variables wave run-up $(\mathrm{R})$ and wave height $(\mathrm{H})$.

All of the geometric, morphological, and hydraulic that influence the wave run-up over both sandy and armoured beaches are summarised in Table 1 . 
Table 1 The classification of parameters affecting wave run-up (sandy beach).

\begin{tabular}{|c|c|c|c|}
\hline 1. Parameters Characterizing the Flow & Symbol & Unit & Dimension \\
\hline Density of Fluid & $\gamma_{w}$ & $\mathrm{Kg} / \mathrm{m}^{2} \mathrm{~s}^{2}$ & $\mathrm{ML}^{-2} \mathrm{~T}^{-2}$ \\
\hline Gravitational Acceleration & $\mathrm{G}$ & $\mathrm{m} / \mathrm{s}^{2}$ & $\mathrm{LT}^{-2}$ \\
\hline Stile Water Depth & $\mathrm{D}$ & $\mathrm{m}$ & $\mathrm{L}$ \\
\hline 2. Parameters Characterizing sand properties & Symbol & Unit & Dimension \\
\hline Density of Sand & $\gamma_{s}$ & $\mathrm{Kg} / \mathrm{m}^{2} \mathrm{~s}^{2}$ & $\mathrm{ML}^{-2} \mathrm{~T}^{-2}$ \\
\hline Diameter of Sand & $D_{s}$ & $\mathrm{~m}$ & $\mathrm{~L}$ \\
\hline 3. Parameters Characterizing Channel Geometry & Symbol & Unit & Dimension \\
\hline Beach Slope & $\beta$ & $\mathrm{m} / \mathrm{m}$ & Dimensionless \\
\hline 4. Wave Characteristic & Symbol & Unit & Dimension \\
\hline Wave Run-up & $\mathrm{R}$ & $\mathrm{m}$ & $\mathrm{L}$ \\
\hline Wave Hight & $\mathrm{H}$ & $\mathrm{m}$ & $\mathrm{L}$ \\
\hline
\end{tabular}

\subsection{Modelling procedures}

The wave run-up height is expressed as a function of the relation between the aforementioned variables using the Buckingham $\pi$-theorem. The similitude or $\pi$-group theorem means the prediction of the prototype performance from the model test observations by the application of $\pi$-group such as Reynolds number or Froude number. The prediction of flow condition using wave models helps to guess the height of the tsunami on the coasts and the possibilityof dispersing these waves for little danger.

$$
\begin{gathered}
R=f\left(\gamma_{w}, d, g, \gamma_{s}, D_{s}, \beta, H\right) \\
f\left(R, \gamma_{w}, d, g, \gamma_{s}, D_{s}, \beta, H\right)=0
\end{gathered}
$$

As $n=8$ (eight variables) and the number of repeated variables are $(m=3)$ chosen as $\left(\gamma_{w}, d\right.$, and $\left.g\right)$, due to $\pi$ theorem, the obtained dimensionless groups are $(n-m=5)$, each one implicates $(m+1=4)$ variables, as presented in the following equations:

$$
\begin{aligned}
& f\left(\pi_{1}, \pi_{2}, \pi_{3}, \pi_{4}, \pi_{5}\right)=0 \\
& \pi_{1}=\gamma_{w}{ }^{a_{1}} * d^{b_{1}} * g^{c_{1}} * R \\
& \pi_{2}=\gamma_{w}{ }^{a_{1}} * d^{b_{1}} * g^{c_{1}} * H \\
& \pi_{3}=\gamma_{w}{ }^{a_{1}} * d^{b_{1}} * g^{c_{1}} * \beta \\
& \pi_{4}=\gamma_{w}{ }^{a_{1}} * d^{b_{1}} * g^{c_{1}} * \gamma_{s} \\
& \pi_{5}=\gamma_{w}{ }^{a_{1}} * d^{b_{1}} * g^{c_{1}} * D_{s}
\end{aligned}
$$

Taking the first group and evaluating $\left(a_{1}, b_{1}\right.$, and $\left.c_{1}\right)$ by expressing the variables in terms of (MLT) as shown below:

$\pi_{1}=\gamma_{w}{ }^{a_{1}} * d^{b_{1}} * g^{c_{1}} * R$

$M^{0} L^{0} T^{0}=\left(\mathrm{ML}^{-2} \mathrm{~T}^{-2}\right)^{a_{1}} *(L)^{c_{1}} * L *\left(L T^{-2}\right)^{b_{1}}$

For M: $a_{1}=0$

For L: $-2 a_{1}+b_{1}+c_{1}+1=0$

$b_{1}+c_{1}=-1$

For T: $-2 b_{1}=0$

$b_{1}=0$

So $\quad c_{1}=-1$

And $\quad \pi_{1}=\frac{R}{d}$ 
By the same way:

$$
\pi_{2}=\frac{H}{d}, \pi_{3}=\frac{D_{s}}{d}, \pi_{4}=\frac{\gamma_{s}}{\gamma_{w}}, \pi_{5}=\beta
$$

$$
\begin{gathered}
f\left(\frac{R}{d}, \frac{H}{d}, \frac{D_{s}}{d}, \frac{\gamma_{s}}{\gamma_{w}}, \beta\right)=0 \\
\frac{R}{d}=f\left(\frac{H}{d}, \frac{D_{s}}{d}, \frac{\gamma_{s}}{\gamma_{w}}, \beta\right)
\end{gathered}
$$

The general form of the analysis can be simplified by some suppositions and according to the circumstances in this study; the term $\frac{\gamma_{s}}{\gamma_{w}}$ represent $G_{S}$ is the specific gravity of sand, the inverse of the term $\frac{D_{s}}{d}$, which is the dimensionless sand diameter will be multiplied by the term $\frac{H}{d}$ we got the term $\frac{H}{D_{S}}$ taking the cot for the beach slop angle $\cot \beta$, is dimensionless slope angle, and $\frac{R}{d}$ is a dimensionless parameter of run-up height, the final form of Eq. (11) becomes as illustrated in the following equation:

$$
\frac{R}{d}=\left(\frac{H}{D_{s}} * G_{s} * \cot \beta\right)
$$

For the gravel beach, we have the same parameters taking into account the gravel-specific gravity $\left(G_{g}\right)$ and gravel diameter $\left(D_{g}\right)$ we have the following equation:

$$
\frac{R}{d}=\left(\frac{H}{D_{g}} * G_{g} * \cot \beta\right)
$$

\section{ANALYSIS STATISTICS}

Following the dimensional analysis described in the previous paragraphs, both of these relationships were applied in the software (IBM SPSS Statistics, v26) for the purpose of creating an empirical formula by using regression analysis for each of the wave Run-up for both sandy and gravel beaches. The curve estimation process generates curve estimation regression statistics, as well as most of the relevant graphs for 10 distinct curve estimation regression models. A unique model is created for each dependent variable, as well as all the independent variables. The predicted values may be kept, while the remainder would be saved as prediction intervals. Regression coefficients, multiple $R, R^{2}$, modified $R^{2}$, standard error of the estimate, analysis-of-variance table, projected values, residuals, and prediction intervals are all included in each model. Linear and nonlinear models, logarithmic, inverse, quadratic, cubic, power, compound, s-curve, logistic, growth, and exponent are some of the terms used in mathematics.

The process of developing a nonlinear model of the relationship that relates a group of independent variables with the dependent variable is defined as a nonlinear regression. It estimates models with any relationship between dependent and independent variables, it differs from standard linear regression, the last can be used to estimate only linear models.

\section{RESULTS}

\subsection{Run up over sandy beach}

The dimensional analysis Equation (12) was used to compensate for the experimental data. Curve estimation analysis was used to determine the correlation ratio and form of relationship between the dependent variable (Run-up) and any of the independent variables (which are represented by: $\mathrm{H}$ ranged between $0.09-0.16 \mathrm{~m}, \beta=$ $1: 10, D_{s}=0.28 \mathrm{~mm}$, and $G_{s}=2.67$ ). Although that the correlation coefficient were $R=0.96$ and $R^{2}=0.92$, the standard error of the approximation was $\mathrm{SSE}=0.022 \%$, and the form of function was cubic, it was discovered that the independent variable defined by the expression $\left(\boldsymbol{H} \frac{G_{s}}{D_{s}} \cot \boldsymbol{\beta}\right)$ is very closely correlated with the dependent variable $(\mathrm{R} / \mathrm{d})$. The estimated values of wave run-up were then obtained using non-linear regression analysis, which was graphically expressed by a best-fit line with the calculated values, as shown in Figure (2). 


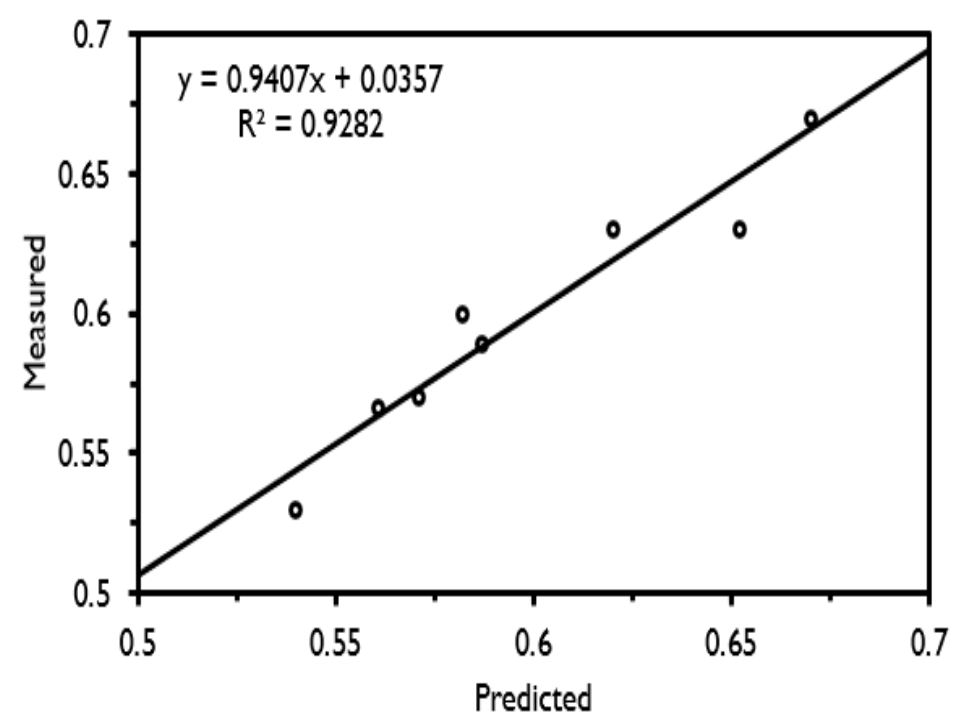

Figure 2 The relation between the experimental and predicted run-up for the sandy beach.

The result clearly shows that excellent estimation is possible, and the association between the observed and expected values is excellent where $\left(R^{2}=93\right)$. As seen in the Equation (14), a new formula was established for calculating the wave run-up as a function of wave height, the specific gravity of sand, particle diameter, and beach slope angle.

$$
\frac{R}{d}=0.041+6.5 * 10^{-5}\left(H \frac{G_{S}}{D_{S}} \cot \beta\right)-1.01 * 10^{-13}\left(H \frac{G_{S}}{D_{S}} \cot \beta\right)
$$

\subsection{Run-up over gravel beach}

In the regression analysis for the wave run-up over gravel beach, the Equation (13) with the experimental data was applied in the SPSS software after the relationship between the dependent variable (wave run-up), with each one of the independent variables (which represented by: $\mathrm{H}$ ranged between $0.07-0.13 \mathrm{~m}, \beta=1: 10, D_{g}=14 \mathrm{~mm}$, and $\left.G_{g}=2.76\right)$ was tested using the curve estimation analysis, where the independent variable that most closely associated with the wave run-up was represented by the term $\left(\boldsymbol{H} \frac{G_{g}}{D_{g}} \cot \boldsymbol{\beta}\right)$ with a correlation coefficient was $(\mathrm{R}=$ 0.99), standard error was $(\mathrm{SEE}=0.009 \%)$, and the function type was cubic.

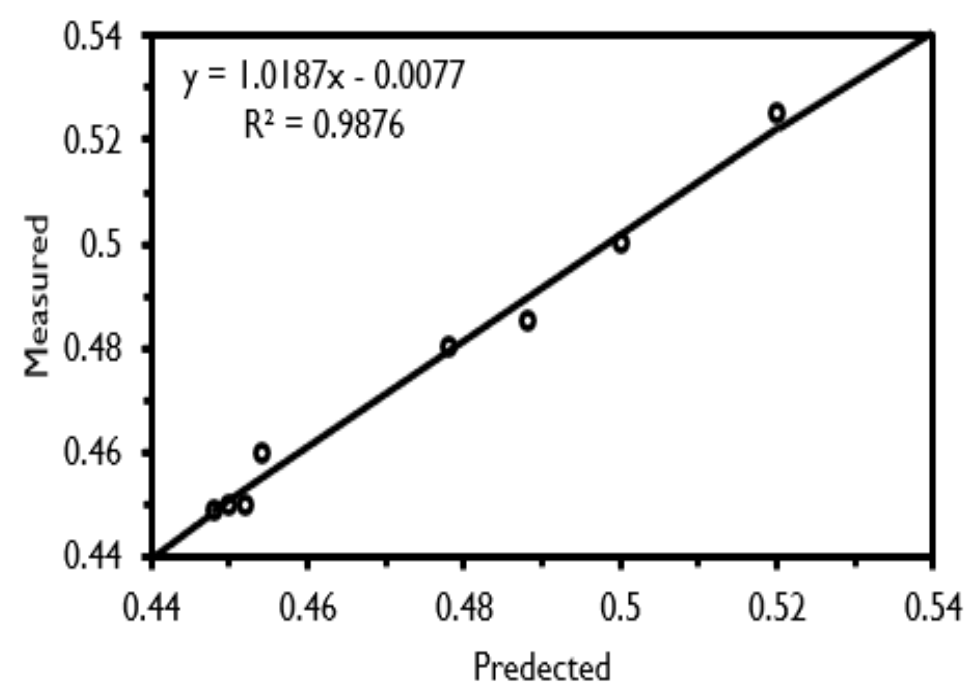

Figure 3 The relation between the experimental and predicted run-up over the armoured beach. 
As shown in Figure (3), the observed values of the wave run-up, which were determined using Equation (13), were plotted with the expected values obtained from the regression analysis by a best-fit axis, where $R^{2}=(98)$. Equation (15) is the developed formula from this analysis that describes wave run-up over gravel beach as a function of wave height, gravel-specific gravity, particle diameter, and the beach slop.

$$
\frac{R}{d}=0.5-4.08 * 10^{-6}\left(H \frac{G_{g}}{D_{g}} \cot \beta\right)+1.5 * 10^{-8}\left(H \frac{G_{g}}{D_{g}} \cot \beta\right)
$$

\section{CONCLUSION}

The current work presented two empirical equations for predicting wave run-up, the first one was used to calculate the magnitude of wave run-up over the sandy beach as a function of wave height, particles diameter, water density, and beach slope. The obtained results showed acceptable compatibility between the calculated and observed values with a 0.93 correlation coefficient. Another one was used to determine the wave run-up over armoured beach for the same parameters and taking into consideration armoured unit diameters, it also showed acceptable compatibility between the determined and observed values with a 0.98 correlation coefficient. The aforementioned formulas were studied depending on data obtained from an experimental test directed using a laboratory flume to examine the wave run-up near the coasts. The obtained results from this study showed that armoured units reduce the wave run-up height by about $30 \%$ in compression to the wave run-up height over the sandy beach.

\section{REFERENCES}

1. Govindasamy N. Mardi N, AMarlinda A (2018) Modeling of Tsunami Forces on Coastal Structures: a Review. International Journal of Engineering and Technology (UAE), 7, 312-316.

2. Brown A (2013) Waves on the horizon. Nature Clim Change, 3, 179. doi.org/10.1038/nclimate1815

3. Kvenvolden K A (1999) Potential effects of gas hydrate on human welfare. Proceedings of the National Academy of Sciences, 96(7), 3420-3426.

4. Masih A (2018) An enhanced seismic activity observed due to climate change: Preliminary results from Alaska. IOP Conference Series: Earth and Environmental Science, 167(1), 012018.

5. Yavuz C, Kentel E, Aral MM (2020) Climate change risk evaluation of tsunami hazards in the eastern mediterranean sea. Water, 12(10), 1-18, doi: 10.3390/w12102881.

6. National Tsunami Hazard Mitigation Program (NTHMP), NTHMP Tsunami Information Guide. National Tsunami Hazard Mitigation Program. 3/2019,

7. Gedik N, İrtem E, Kabdasli S (2005) Laboratory investigation on tsunami run-up. Ocean Engineering, 32(5-6), 513-528.

8. Ghasemi, S. (2011). Study of Tsunamis by Dimensional Analysis. Engineering, 3(9), 905.

9. Charvet I, Eames I, Rossetto T (2013) New tsunami runup relationships based on long wave experiments. Ocean Modelling, 69, 79-92.

10. Synolakis C E (1987) The runup of solitary waves. Journal of Fluid Mechanics, 185, 523-545.

11. Aldefae A H, Shamkhi M S, Khalaf T (2019) Design and manufacturing of geotechnical laboratory tools used in physical modeling. Cogent Engineering, 6(1), 1637622.

12. Aldefae A H, Alkhafaji R A, Shamkhi M S, Kumer H Q (2019). Design and manufacturing of flume apparatus to investigate the failure mechanism of riverbanks. Cogent Engineering, 6(1): 1655234 
13. Sorensen R M (2006). Basic coastal engineering, Springer Science, pp. 324.

14. Rossetto T, Allsop W, Charvet I, Robinson D I (2011) Physical modelling of tsunami using a new pneumatic wave generator. Coastal Engineering, 58(6), 517-527.

15. Aldefae A N, Aldefae A H (2020) Seismic performance of gravity quay wall. IOP Conference Series: Materials Science and Engineering, 1058(1), 012033.

16. Aldefae A H, Alkhafaji R A (2021) Experimental and numerical modeling to investigate the riverbank's stability. SN Applied Sciences, 3(2), 1-6.

17. Saadon A, Ariffin J, Abdullah J, Daud N M (2016) Dimensional analysis relationships of streambank erosion rates. Jurnal Teknologi, 78(5-5), 79-85. 